\title{
POST-STERILIZATION REGRETS IN INDIAN WOMEN
}

\author{
NEENA MALHOTRA, CHARU CHANANA, PRADEEP GARG
}

\section{ABSTRACT}

BACKGROUND: Tubal ligation is the most common form of contraception in India. We conducted this study to assess the factors associated with post-sterilization regrets. AIMS: This study was designed to assess risk factors that are likely to cause regret following female sterilization in Indian women. SETTINGS AND DESIGN: Questionnaire-based study. MATERIALS and METHODS: This was a questionnairebased study to assess the level of satisfaction after tubal ligation in women attending family planning clinic at the hospital over a period of 1 year. Evaluation of data obtained through questionnaire from 236 women who had undergone tubal ligation was done. STATISTICAL ANALYSIS: Univariate analysis to determine crude odds ratio was carried out. Subsequently, multiple regression analysis was used to find the adjusted odds ratio (and 95\% confidence intervals) for each variable. RESULTS: We found a strong corelation between regrets and young age (less than 30 years), fewer number of children, few or no male children and lack of partner motivation prior to sterilization. Menstrual irregularities and dysmenorrhoea did not influence regret to a large extent. CONCLUSION: Fertility-related factors, namely, age at sterilization, family size, number of male offspring, timing of sterilization and non-involvement of partner in decision making played a greater role in post-sterilization regrets than menstrual factors (menstrual irregularities and dysmenorrhoea).

Key words: Female sterilization, regrets after sterilization

Female sterilization is the world's most popular contraceptive method. In India, female sterilization has been the mainstay of National Family Welfare program, accounting for $84 \%$ of prevalence among married couples using modern methods. ${ }^{[1]}$ Current statistics reveal that in the year 2000-2001, 4.74 million women underwent sterilization. ${ }^{[2]}$ Age at marriage continues to be low in India, and a vast majority of women complete their

Department of Gynecology and Obstetrics, All India Institute of Medical Sciences, New Delhi, India

\section{Correspondence}

Dr. Charu Chanana, 91, Pocket B, Sukhdev Vihar, New Delhi, India.

E-mail: charuchanana@rediffmail.com families in the early twenties. In the current social milieu of stable marriages, sterilization is the commonest method, even for younger married couples. ${ }^{[3]}$ With growing tendency of more women undergoing tubal ligation at a younger age, there is a potential for poststerilization regret. ${ }^{[4]}$ Even a small population of women developing post-sterilization regret would translate into a large number of sufferers in later years. Studies on poststerilization regret are available from developed countries. ${ }^{[5,6]}$ The situation in less developed countries, where tubal occlusions are more commonly performed, is virtually unknown. Moreover, most studies on post- 
sterilization regret date back to the $70 \mathrm{~s}$, and since then there have been social and cultural changes, justifying a recent study on post-sterilization regret. To assess the extent of satisfaction or regret and the factors causative for regrets among Indian women, this follow-up study was conducted.

\section{MATERIALS AND METHODS}

A questionnaire-based study was conducted to assess the level of satisfaction after tubal ligation in women attending family planning clinic at the hospital over a period of 1 year. The study period of 1 year included questionnaire planning, interview, data entry and subsequent analysis. In this clinic-based study, women were interviewed using the defined questionnaire [Appendix]. Due to the lack of available database for follow-up, all women were interviewed at one occasion only; regret during later years would be meaningful if the same women were re-interviewed at a later date, which is not possible in our setup as we do not maintain a database of our sterilized women. The study protocol was approved by the Departmental Expert Board, and an informed consent was obtained from every couple participating in the study. Those who agreed to respond to the questionnaire were recruited for the study. Two hundred seventy-seven women were enrolled in the study, of which $57 \%$ women came for followup after sterilization in the same hospital and the remaining $43 \%$ were followed up after sterilization done at other hospitals. The women were interviewed by the same investigators (NM and $\mathrm{PKG}$ ) and confidentiality was ensured. Variables considered during interview included age at sterilization, time since sterilization, parity, number of living children, gender distribution and timing of sterilization (postpartum, interval, concurrent abortion or cesarean section). They were further interviewed on use of previous contraceptive methods, knowledge of reversibility of procedure and involvement of male partner in decision making.

Satisfaction with tubal ligation was considered in response to questions such as 'Do you think tubal ligation as a permanent method of birth control was a good choice?' Those who answered 'no' were further asked, 'Would you choose tubal ligation as a method of birth control if given another option?' If the answer was a consistent 'no,' then this group was considered to have regretted the decision. Further questioning continued to seek reasons for regret. This included interrogation regarding menstrual irregularities, dysmenorrhoea and psychosexual complaints, besides medical problems.

Women with loss of a child; sterilization failure; breakup of marital union with subsequent remarriage, where women would request reversals, were excluded $(n=24)$ from the analysis to prevent any bias and increased rate of regret that would arise from these factors. Further, women with ambivalent thoughts were also excluded $(n=$ 27). This left 236 women in the final analysis.

\section{Statistical analysis}

Data from questionnaires was entered into a personal computer and analyzed using the statistical package SPSS (version). Data was examined on univariate basis to determine crude odds ratio for each variable of interest. Statistical significance was established by means of Chi-square test with Yate's correction or Fischer's exact test for small expected frequencies. The confidence limits of the odds ratio were calculated by means of the method of Cornfield. All variables with a probability of an association value less than 0.05 in the crude analysis were assessed together by use of multiple logistic regression model to determine their importance after simultaneous adjustment of other variables. The adjusted odds ratios with $95 \%$ confidence intervals were evaluated for these variables.

\section{RESULTS}

The mean age of women at the time of ligation in our study was $28 \pm 4.87$ years [Table 1]. Of the 236 women, 22 regretted their decision of sterilization with a regret rate of $9.3 \%$. The mean time interval between sterilization and regret was $5 \pm 2.31$ years.

The risk factors likely to cause regret as assessed on regression analysis are suggested in Table 2. Different proportions of regret were noted in different age groups. Regret declined as age increased. A significant difference between women regretting versus those not regretting was found in those less than 30 years

Table 1: Demographic profile of women

\begin{tabular}{|c|c|c|}
\hline & Satisfied $(n=214)$ & Regret $(n=22)$ \\
\hline Age at sterilization & & \\
\hline $\begin{array}{l}<24 \\
25-29\end{array}$ & $\begin{array}{l}42 \\
79\end{array}$ & $\begin{array}{l}6(12.5) \\
11(12.2)\end{array}$ \\
\hline $30-34$ & & $\begin{array}{c}11(12.2) \\
3(5.3)\end{array}$ \\
\hline & & $2(4.8)$ \\
\hline \multicolumn{3}{|l|}{ Religion } \\
\hline Hindu & 19 & $18(9.4)$ \\
\hline Muslim & 65 & $1(20)$ \\
\hline Christians & 35 & $3(9.6)$ \\
\hline \multicolumn{3}{|l|}{ Socio-economic status } \\
\hline Low & 93 & $11(10.5)$ \\
\hline Middle & 84 & $9(9.6)$ \\
\hline High & 37 & $2(5.1)$ \\
\hline \multicolumn{3}{|l|}{ Education } \\
\hline Illiterate & 69 & $11(13.7)$ \\
\hline Primary & 41 & $5(10.8)$ \\
\hline Secondary & 56 & $4(6.6)$ \\
\hline \multirow{2}{*}{\multicolumn{3}{|c|}{ Parity }} \\
\hline & & \\
\hline $0-2$ children & 75 & $12(13.7)$ \\
\hline 3-4 children & 111 & $9(7.5)$ \\
\hline$>5$ children & 28 & $1(3.4)$ \\
\hline
\end{tabular}

Indian J Med Sci, Vol. 61, No. 4, April 2007 and those above the age of $30(P=0.01)$ Timing of sterilization influenced regret frequency of regret being higher in those women who were ligated at the time of cesarean section than those who had interva ligation or were sterilized after termination of pregnancy [Table 2].

Table 2a: Parameters responsible for regret

\begin{tabular}{|c|c|c|}
\hline \multirow{2}{*}{\multicolumn{3}{|c|}{ Variable }} \\
\hline & & \\
\hline $\begin{array}{l}>30 \\
>30\end{array}$ & $1.0^{*}$ & 0.01 \\
\hline $\begin{array}{r}<30 \\
\text { Parity }\end{array}$ & 1.8 & \\
\hline $\begin{array}{l}\text { Parity } \\
<2 \text { children }\end{array}$ & & 0.029 \\
\hline $\begin{array}{l}3-4 \text { children } \\
>5 \text { children }\end{array}$ & 0.50 & 0.025 \\
\hline Iale child & & \\
\hline & $\begin{array}{l}1.0^{*} \\
2.54 \\
1.9\end{array}$ & $\begin{array}{l}0.013 \\
0.029\end{array}$ \\
\hline $\begin{array}{l}\text { Husband's mo } \\
\text { No }\end{array}$ & & \\
\hline $\begin{array}{l}\text { No } \\
\text { Yes }\end{array}$ & $\begin{array}{l}1.0^{*} \\
0.32\end{array}$ & 0.02 \\
\hline Menstrual proble & & \\
\hline $\begin{array}{l}\text { No } \\
\text { Yes }\end{array}$ & $1.0^{*}$ & 0.27 \\
\hline Timing of steriliz & & \\
\hline Interval & 0.812 & 0.44 \\
\hline $\begin{array}{l}\text { At caesarean } \\
\text { At abortion }\end{array}$ & $\begin{array}{l}1.0^{*} \\
0.90\end{array}$ & 0.05 \\
\hline
\end{tabular}

*Reference value

Table 2b: Parameters responsible for regret

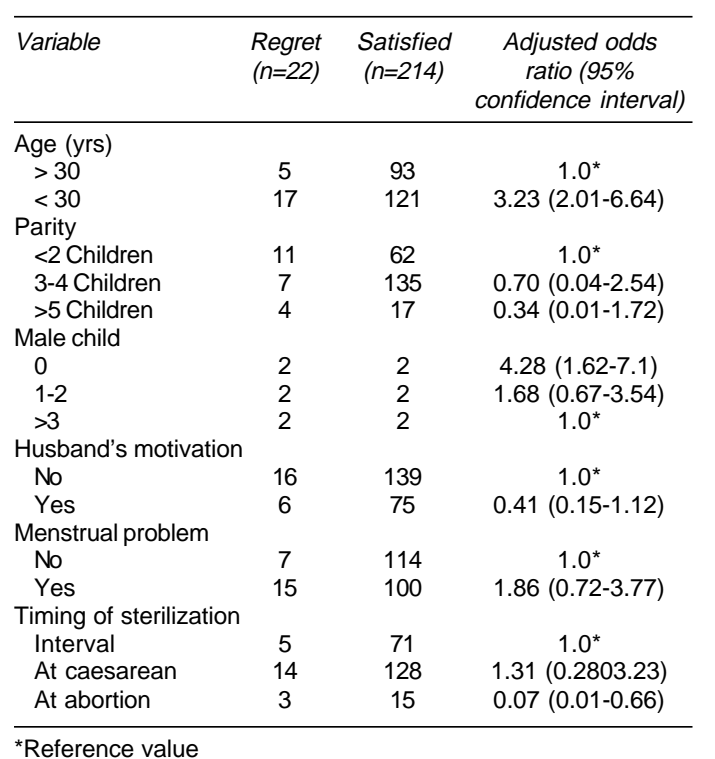


As was anticipated in the Indian society, no or fewer number of male offspring was responsible for regret in a large number of women. The women who had two or three and more sons were less likely to regret decision of sterilization in comparison to women with no male issues $(P=0.013,0.029$ respectively). Also it was seen that women with less number of children $(<2)$ at time of ligation had an increased likelihood to regret their decision. Involvement of the male partner in decision making influenced regret and caused fewer women to regret their decision.

Few women reported changes in their menstrual patterns, and some had dysmenorrhoea after sterilization. But regret due to this cause was not statistically significant.

The results point towards the fact that fertility-related reasons contributed significantly towards regrets after sterilization in contrast to menstrual reasons.

\section{DISCUSSION}

There is an overall global estimate of $2-13 \%$ women regretting sterilization from 6 months to 6 years post-sterilization. ${ }^{[7]}$ Regret at sterilization has varied with its definition and society. Definition of regret after sterilization varied considerably in previous studies. ${ }^{[4,5]}$ Questions asked to measure regret included whether respondents were satisfied, pleased, dissatisfied or sorry about sterilization. Some studies asked if those who expressed regret would want reversal, but none expressed this desire in our study. ${ }^{[8]}$ Studies about post- sterilization regret have been mostly from developed societies; studies regarding situation from less developed societies have been limited even though tubal ligations are performed more commonly in less developed countries.

Our study suggested fertility-related factors to be stronger predictors of regret as compared to menstrual reasons, as found in other studies. ${ }^{[4-6]}$ Age less than 30 years was the strongest risk factor in our study, as reported previously. Women $<30$ years were 1.8 times more likely to regret sterilization. Women under 30 years need greater counseling as compared to older women. Also such women need to be offered alternative methods of contraception. Even though MIRENA and Implanon are currently not available in the national family planning program, other temporary methods as copper $T$ and oral pills should be offered before a decision is taken for sterilization in women less than 30 years.

Parity and interval since sterilization were not concurrent factors for sterilization regret. Whether parity is or not a risk factor for regret probably depends on the family size standard in a society. ${ }^{[4]}$ India is fast adopting a smaller family size, and this could modify our observation. The desire for a male child was an important factor predicting poststerilization regret. Son preference is stronger as women's status is low and girls are devalued in most northern states of India. Therefore, regret is expected more among those who have fewer or no sons. Regrets were lesser when husbands were involved in decision making, in contrast to some studies from developing countries, ${ }^{[9,10]}$ where women were more likely to regret sterilization when husband recommended the procedure. Probably in a gender-stratified society, men play a pivotal role in decisions related to sexual and reproductive health matters. ${ }^{[11,12]}$ Therefore, it is obvious that women are less likely to regret when the decision was initiated and supported by male a partner.

Results of our study in terms of factors determining post-sterilization regret in Indian women were quite similar to a study that analyzed causes of regret in the Puerto Rican population. Factors associated with regret in this population were young age at sterilization, absence of daughters (absence of son or less number of sons in our study), someone else making the decision to be sterilized, medical indications for sterilization, sterilization failure and living with a new marital partner. There were no significant effects associated with the timing of sterilization, whether interval or postpartum, or with the type of last delivery. Other factors not independently associated with regret included years since sterilization, parity, education and age at follow-up. ${ }^{[12]}$

Knowledge of risk factors which have a strong association with regret and are easily identifiable before sterilization is definitely useful in counseling to prevent regrets. Motivators who may not be doctors or paramedics all the time in our society need to be aware of the risk factors prior to counseling women for sterilization. Women undergoing interval sterilization were less likely to regret in comparison to those who had the procedure concurrent with cesarean section.
This observation of ours was contrary to the crest study in which the researchers found that although young age at sterilization was an important factor for regret, the timing of sterilization did not alter the incidence of regret after the sterilization procedure. ${ }^{[5]}$ The implications of such results have been reported earlier and mean that sterilization as a contraceptive choice should be discussed in the antenatal period rather than be a stressed decision just before surgery. ${ }^{[4,5]}$

$$
2
$$

Though post-sterilization regret is no extremely avoidable, certain groups such as younger women $<30$ years, those undergoing sterilization at cesarean section and women who are not fully motivated or do not have support of husbands before taking such a major decision like sterilization need specia counseling.

\section{REFERENCES}

1. Registrar general and census commission India Series 1. Census of India: 2001.

2. Family welfare programme in India, Department of family welfare, Ministry of Health and Family Welfare: New Delhi; 2001.

3. Pachauri S, Santhya KG. Reproductive choices for Asian adolescents: A focus on contraceptive behaviour. Int Fam Plan Prospect 2002;28:18695.

4. Chi IC, Jones DB. Incidence, risk factors, and prevention of poststerilization regret in women: An updated international review from an epidemiological perspective. Obstet Gynecol Surv 1994;49:722-32.

5. Hillis SD, Marchbanks PA, Tylor RL, Peterson HB. Poststerilization regret: Findings from the United States Collaborative Review of Sterilization. Obste Gynecol 1999;93:889-95. 
6. Platz-Christensen JJ, Tronstad SE, Johansson O, Carlsson SA. Evaluation of regret after tubal sterilization. Int J Gynecol Obstet 1992;38:223-6.

7. Liskin L, Rhinenar W, Blackburn R, Rutledge AH. Minilaparotomy and laparoscopy-safe, effective and widely used. Popul Rep C 1985;9:C125-67.

8. Kariminia A, Saunders DM, Chamberlain M. Risk factors for strong regret and subsequent IVF request after having tubal sterilization. Aust NZJ Obstet Gynaecol 2002;42:526-9.

9. Male and Female sterilization-Evidence based clinical guideline No.4. Royal College of Obstetricians and Gynecologists: Jan 2004.

10. Pachauri S. Expanding contraceptive choices in India Issues and evidence. J Fam Welfare 2004;50:13-25.

11. Bertrand JT, Kashwantale C, Balowa D, Baughman NC, Chirwisa C. Social and psychological aspects of tubal ligation in Zaire: A follow- up study of acceptors. Int Fam Plan Perspect 1991;17:100-7.

12. Boring CC, Rochat RW, Becerra J. Sterilization regret among Puerto Rican women. Fertil Steril 1988;49:973-81.

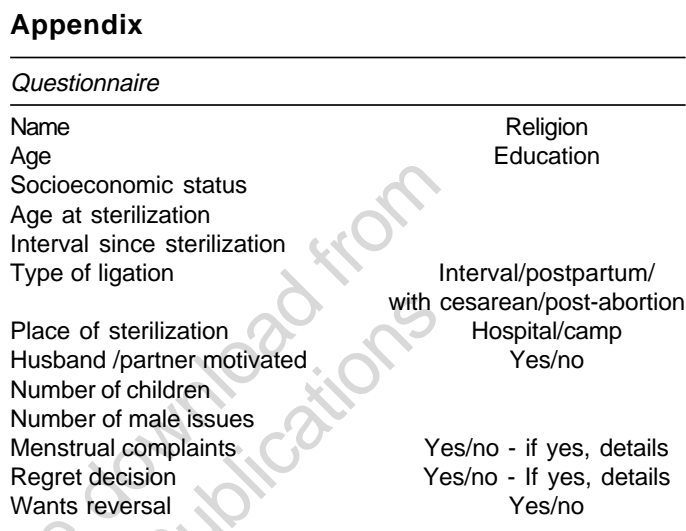

Source of Support: Nil, Conflict of Interest: None declared.

\section{Author Help: Reference checking facility}

The manuscript system (www.journalonweb.com) allows the authors to check and verify the accuracy and style of references. The tool checks the references with PubMed as per a predefined style. Authors are encouraged to use this facility before submitting articles to the journal.

- The style as well as bibliographic elements should be $100 \%$ accurate to get the references verified from the system. A single spelling error or addition of issue number / month of publication will lead to error to verifying the reference.

- Example of a correct style

Sheahan P, O'leary G, Lee G, Fitzgibbon J. Cystic cervical metastases: Incidence and diagnosis using fine needle aspiration biopsy. Otolaryngol Head Neck Surg 2002;127:294-8.

- Only the references from journals indexed in PubMed would be checked.

- Enter each reference in new line, without a serial number.

- Add up to a maximum 15 reference at time.

- If the reference is correct for its bibliographic elements and punctuations, it will be shown as CORRECT and a link to the correct article in PubMed will be given.

- If any of the bibliographic elements are missing, incorrect or extra (such as issue number), it will be shown as INCORRECT and link to possible articles in PubMed will be given. 